\title{
The EU Energy Poverty and Vulnerability Agenda: An Emergent Domain of Transnational Action
}

Link to publication record in Manchester Research Explorer

\section{Citation for published version (APA):}

Bouzarovski, S., Petrova, S., Tosun, J. (Ed.), Biesenbender, S. (Ed.), \& Schulze, K. (Ed.) (2015). The EU Energy Poverty and Vulnerability Agenda: An Emergent Domain of Transnational Action. In Energy Policy Making in the EU (pp. 129-144). Springer Nature. http://link.springer.com/chapter/10.1007/978-1-4471-6645-0_7

\section{Published in:}

Energy Policy Making in the EU

\section{Citing this paper}

Please note that where the full-text provided on Manchester Research Explorer is the Author Accepted Manuscript or Proof version this may differ from the final Published version. If citing, it is advised that you check and use the publisher's definitive version.

\section{General rights}

Copyright and moral rights for the publications made accessible in the Research Explorer are retained by the authors and/or other copyright owners and it is a condition of accessing publications that users recognise and abide by the legal requirements associated with these rights.

\section{Takedown policy}

If you believe that this document breaches copyright please refer to the University of Manchester's Takedown Procedures [http://man.ac.uk/04Y6Bo] or contact uml.scholarlycommunications@manchester.ac.uk providing relevant details, so we can investigate your claim.

\section{OPEN ACCESS}




\title{
The EU energy poverty and vulnerability agenda: An emergent domain of transnational action $^{1}$
}

\author{
Stefan Bouzarovski and Saska Petrova
}

\section{Introduction: Addressing energy poverty at the European scale}

In decision-maker and academic circles alike, the concept of 'EU energy policy' is generally associated with measures to address residential and industrial consumption practices, or trans-national security issues. There is little recognition or knowledge of the fact that the EU is becoming increasingly involved in a new strategic effort situated at the nexus among household fuel use, affordability, and residential energy efficiency. In the main, this process is mainly associated with the intensifying drive to formulate and implement panEuropean policies aimed at preventing and ameliorating energy (or fuel) poverty -a condition where a household is unable to access energy services in the home to a socially and materially acceptable level (Bouzarovski et al. 2012).

The relative invisibility of EU energy poverty policies can be attributed to the fact that debates around the social and housing dimensions of energy use have traditionally received little attention at the national scale within most member states. The UK and Ireland

\footnotetext{
${ }^{1}$ The research leading to these results has received funding from the European Research Council under the European Union's Seventh Framework Programme (FP7/2007-2013)/ERC grant agreement number 313478. Stefan Bouzarovski is also a Visiting Professor at the Department of Economic Geography, University of Gdansk, Poland.
} 
represent a notable exception; the condition of 'fuel poverty' received early political recognition in these two countries, albeit with considerable political difficulty (Boardman 2010). The last five years, however, have seen an increasing acknowledgment of the European energy poverty problem by decision-makers across the continent. This trend has been motivated, in part, by growing public concerns over the affordability of energy: An issue that reached major proportions in the case of Bulgaria, leading to the downfall of the country's government in 2012 .

The rising recognition of energy poverty has been accompanied by the emergence of a number of new regulatory documents, policy proposals and high level discussions on the topic. But the emergence of a new polity with respect to the understanding of energy poverty as a genuinely pan-European problem has not been associated with a commensurate amount of academic attention.

There is little appreciation of the systemic processes that lie behind the political acceptance of energy poverty at the European scale, especially in terms of the power actors, interests and relations that have driven the increasing prominence of this issue within EU regulation and debates. This situation has transpired despite the fact that the constituent dynamics of some of the political developments and institutional structures associated with adjacent programmatic sectors are well known (for example, there is a sizeable body of research of the underlying principles and implementation challenges associated with EU policy in the environmental policy and security domains - see McCormick 2001). It is also necessary to understand how the various emergent components of EU policy on the subject are being influenced, shaped, and accepted by member states themselves.

Updating the results of an earlier study (Bouzarovski et al. 2012) this chapter explores the organizational and political complexities surrounding the adoption of energy poverty agendas and policies at the EU decision-making level. Theoretical insights from the policy mobilities literature (see Peck 2011; McCann and Ward 2012) have been employed towards an empirical exploration of the actors, interests and power relations discourses implicated in the entrance and proliferation of energy poverty concerns into the EU political agenda. Our dependent variable, therefore, is the process of agenda shap- 
ing within the EU's emergent energy poverty policy. This has been examined with the aid of a triangulation of data from the secondary literature and interviews in various EU institutions; 15 such interviews were undertaken during 2011 and 2012 - their results are presented summarily in the chapter as the surveyed individuals asked that their identities are kept confidential.

In positing our empirical explorations, we draw upon the emergent body of work on the nature of agenda-setting processes at the EU level. As such, energy poverty policies at the European scale can be seen as part of the broader policy effort in the EU energy poverty domain, which is often being seen as 'driven by events' and subject to 'soft' governance mechanisms (Tosun et al, this volume; and Tosun and Solorio 2011). Authors working in this vein have also argued that 'despite the centrality of climate change concerns in the rhetoric of the European Commission, an effective integration of environmental goals into energy policy is difficult to achieve' (Tosun and Solorio 2011: 1). Their findings are inspired by the broader literature on agenda setting, where it is contended that the definition and identification of a problem plays a key role in consequential policy stages, and that the process can take place in both a bottom-up and top-down manner while involving multiple international actors (Cobb and Elder 1983). In the text that follows, we explore the extent to which some of these claims hold true in the case of European energy poverty.

The analysis of the evidence that we have gathered is presented in three sections: in the first, we examine the broader regulatory framework relevant to the intersection between energy affordability, energy efficiency and social welfare, while the second discusses the origins of direct EU energy poverty policies as they relate to initial efforts to create an agenda in this domain. Then follows a section that scrutinizes the more recent role and activities of various organizations in this domain, so as to provide an account of the emergent political discourses aimed at encapsulating the driving forces of, and mitigating strategies for, energy poverty in Europe. The conclusion evaluates the success of policies to date, while highlighting the pathways that have allowed for action aimed at addressing the domestic energy deprivation of European households to become 'mo- 
bile'. We also speculate on the likely future development of EU activities in this sphere.

\section{Energy poverty: key underpinnings}

Before proceeding to discuss the evolution of EU policies in the energy poverty domain, it is worth briefly exploring the wider theoretical and practical issues associated with the conceptual intersection among energy, poverty and housing. As was noted above, this is an area which has often remained invisible to politicians and scientists alike - indeed, a government minister in the UK infamously claimed that "people do not talk of "clothes poverty" or "food poverty", and I do not think that it is useful to talk of "fuel poverty" either' (Campbell 1993: 58). When seen in this context, it is easy to see why and how the early establishment of a clear 'fuel poverty' definition in the British academic and decision-making polity was so groundbreaking. Indeed, it was the UK where the first comprehensive state policies to address fuel poverty were created, in addition to the emergence of integrated scientific debates about the driving forces and consequences of living in homes with inadequate energy services.

The initially-established interpretation of fuel poverty in the UK where this condition is principally seen as the inability to purchase affordable warmth - remained in place for more than 20 years, being resistant to outside criticism. Until a few months ago, fuel poverty in the UK was described as a situation in which a household needs to spend more than 10 per cent of its total income (before housing costs) on all fuel used to heat its homes to an acceptable level (Bouzarovski 2013). Two aspects of this definition have been particularly controversial in the scientific and policy-making community: First, 'needing to spend' refers not to actual expenditure, but to a hypothetical level that is closely related, inter alia, with the thermal energy efficiency of the dwelling (ibid); Second, 'acceptable level' is taken to mean that the home is heated in line with the standards recommended by the World Health Organization (WHO) $-18{ }^{\circ} \mathrm{C}$ for bedrooms and $20-21^{\circ} \mathrm{C}$ for living rooms (ibid).

The UK now uses a definition of fuel poverty based on the findings of a recent government-sponsored review undertaken by Professor 
John Hills at the London School of Economics. The background work for report involved involving multiple stages of consultation with experts, non-governmental organizations and think tanks involved in the topic. Having concluded that the existing UK definition has resulted in a situation whereby fuel poverty statistics are too sensitive to movements in gas and electricity bills as well as 'the precise assumptions made for what are seen as adequate temperatures for people to live at, and the incomes reported to a survey that is mainly not focused on income measurement', the report suggested that the government adopt a new indicator about the extent of fuel poverty, which would consider households poor if i) their 'required fuel costs' are above the median level for the entire population; and ii) spending that amount would leave them 'with a residual income below the official poverty line' (Hills 2012).

In essence, controversies around the definition of fuel poverty in the UK reflect a broader unease among academics and policy makers alike, with respect to the methods and approaches for measuring the incidence and character of inadequate energy services in the home. This has traditionally been an extremely challenging task in light of the specific nature of the problem, which is:

- difficult to detect, due to being private and confined to the domestic domain by its very nature;

- $\quad$ highly variable over time and space, since an individual may fall in and out of fuel poverty at many stages during the life course, and the extent of domestic energy deprivation experienced by one household may be very different to that of its neighbours;

- $\quad$ sensitive to cultural and social context, since expectations and perceptions of energy services in the home are highly subjective.

Statisticians, researchers and decision-makers have used three types of methods to observe and measure fuel poverty. Some of them have employed direct surveys to examine the level of energy services (space heating or cooling, lighting, refrigeration and so on), subsequently comparing the obtained values to a given standard. In most cases, however, they have relied on analyses of the extent to 
which patterns of household energy expenditure across the population vary in relation to pre-set absolute and relative lines. A distinct strand of work has focused on obtaining the subjective impressions of households about the level of energy service obtained in the home.

It should be pointed out that the first approach has not been used on a large scale within the EU, due to the technical impracticalities and ethical issues associated with it (Bouzarovski 2013). Adding to this are the difficulties of defining adequate energy service standards, due to, in part, cultural specificities: As was pointed out above, it is known that a home normally considered well-lit and warm in one geographical context may not be seen as such in another (ibid). But national statistical agencies across the EU do gather expenditure data via household budget surveys, which, when combined with census data and information compiled through other research studies, have allowed experts to identify the depth of fuel poverty. Other than a limited number of countries and international organizations (such as the World Bank) this method of energy poverty data collection has not found much policy application.

At the same time, EU debates on questions of domestic energy deprivation have largely been influenced by self-reported data relevant to energy poverty collected principally Eurostat's Statistics on Income and Living Conditions survey (or SILC, preceded between 1994 and 2001 by the European Community Household Panel ECHP) as well as national statistical agencies. SILC and ECHP 'consensual' indicator about the share of population which feels that it is 'unable to keep the home adequately warm' has provided the only directly-relevant and internationally comparative tool for judging the extent of energy poverty at the EU scale. These surveys have often been cited in - and provided the motivation for -international action on the issue due to collecting various objective data about dwelling quality and the material conditions of households, which allows for self-reported views of thermal comfort to be crossreferenced against other built environment and economic strain indicators. However, various experts working in the field have often questioned the quality of these sources, while emphasizing that they do not contain enough relevant information to make informed policy decisions. 
EU action on the energy poverty front has been further complicated by the multiple meanings of the concept of 'fuel poverty', since numerous related concepts have been used to describe this condition in other settings. This includes, inter alia, notions of 'energy precariousness', and 'energy deprivation', as well as more narrow terms that refer to some of the symptoms of this condition, such as 'cold homes', 'energy non-payment' or 'energy disconnection'. The existence of a distinct body of research on 'energy poverty' in the developing world also needs to be noted here: Such work has mainly been focused on investigating and ameliorating the consequences of inadequate access to 'modern' energy services, as a result of the lack of adequate energy infrastructure. In recent years, various scholars have started to use an 'energy vulnerability' framework to emphasize the technically and temporally precarious nature of access to energy services per se. Insights from the 'capabilities' approach and relative poverty have also been added to the equation.

\section{European policies to address the energy-housing-poverty nexus: Setting the context}

Despite the scarcity of academic research on the extent and depth of European energy poverty, there is now a sufficient body of evidence to suggest that this predicament is widespread across the continent, where it is likely to affect millions of households. The lack of adequate energy services in the home is particularly pronounced in Southern and Eastern European states, mainly due to their overall higher rates of general income poverty and energy inefficient dwellings. Nations situated on the 'Atlantic Rim' - Ireland, the UK, France and Belgium - are also seen as vulnerable to above average rates of domestic energy deprivation (Bouzarovski 2013).

However, many European governments have traditionally refused to recognize the existence of an energy poverty problem on their territory, let alone the whole of the EU. This means that energy poverty is rarely seen as a European issue - a situation that is further exacerbated by the fact that the alleviation of more general income poverty and social exclusion is primarily a responsibility of the EU's member states. Yet the rootedness of this predicament in broader hous- 
ing, social welfare and infrastructural systems means that member state-level efforts to address it have often been indirectly affected by EU legislation in related spheres. For example, considering that the inadequate energy efficiency of the housing and appliance stock is one of the main driving forces of energy poverty, it can be said that European policy in the energy sector has played an important ancillary role in addressing domestic energy deprivation. This is particularly true in the case of:

- Directive 2010/31/EU on the Energy Performance of Buildings (a recast of the Directive 2002/91/EC), which addresses housing conditions through better energy efficiency of buildings - thus helping address some of the causal factors of energy poverty. Each member state is obliged to develop its own methodology to implement the goals of this Directive;

- Directive 2010/30/EU on the labeling and standard product information of the consumption of energy and other resources by energy-related products - inefficient appliances are a key contributor to energy poverty;

- Directive 2006/32/EC on energy end-use efficiency and energy services, repealing Council Directive 93/76/EEC;

- Directives for labeling various household appliances (94/2/EC,95/12/EC,95/13/EC, 96/60/EC, 97/17/EC, 98/11/EC,2001/40/EC and 2002/31/EC),

- Directives 2003/54/EC and 2003/55/EC, which provide for the right of consumers to have a contract with their energy provider, the right to receive transparent information on prices, and the right to be given adequate notice if contractual conditions are changed. These have been crucial in addressing the position of vulnerable consumers vis-à-vis utility companies (it is often the case that energy poor households pay, on average, higher energy prices than the rest of the population);

- Directive 2005/29/EC, which outlaws unfair commercial practices, also including the energy sector. 
Also significant in this context is the European Commission's communication titled 'Energy 2020 - A strategy for competitive, sustainable and secure energy'. It defines the bloc's energy priorities until 2020, and sets the actions to be taken in order to tackle the multiple challenges of saving energy, achieving a market with competitive prices and secure supplies, boosting technological leadership, and effectively negotiating with the EU's international partners. While issues surrounding intra-EU energy co-operation are left open, policy proposals within the document include a number of energy-poverty relevant topics:

- The management of internal energy markets, such as the strengthening of regulation to increase competition, consumer protection and increase of security of supply;

- Infrastructure, such as gas pipelines and interconnectors between national electricity and gas networks, simplified procedures for permissions and financing, as well as.

- Energy efficiency, which could include strengthening ecodesign regulation, financing, and revisions of the Energy service and CHP directives.

A degree of spillover into the domain of energy poverty can also be found in relation to EU policies to reduce regional, economic or social inequalities. The 2000 Lisbon summit in particular provided an important political push towards poverty amelioration. At this gathering, a decision was made for member states to co-ordinate their policies for combating poverty and social exclusion on the basis of the 'open method of co-ordination' - a determination which has resulted in the adoption of an increased number of legal and policy instruments by relevant European bodies. The EU's commitment in this context has been reflected, for example, by the launch of the 'European Year Against Poverty and Social Exclusion' in January 2010. Also of relevance is the Commission's Communication titled 'Europe 2020 - A Strategy for Smart, Sustainable and Inclusive Growth', which is strongly focused on social cohesion and fighting poverty through, inter alia, measures in the energy sector (mainly energy efficiency and renewable energy sources). The key element and one of the seven flagships - of 'Europe 2020' is the 'Platform 
Against Poverty and Social Exclusion', which has helped promote a set of innovative approaches for addressing poverty and social exclusion in member states and candidate countries. The Platform is aimed at creating a joint commitment among the Member States, EU Institutions and the stakeholders to fight poverty and social exclusion.

It should also be pointed out that the European energy poverty sphere has also been influenced by the activities of the Council of Europe $(\mathrm{CoE})$ in the domain of housing policy. They are comprehensively reflected in a $\mathrm{CoE}$ report on this issue (Council of Europe 2008), drafted by the Group of specialists on housing policies for social cohesion. The report aims to aid the improvement of housing access among vulnerable social groups in Europe. It has resulted in a set of specific guidelines, which stipulate the key prerequisites for an effective housing policy in this domain, while listing a range of potential policy tools. Such efforts have been further assisted by the increasing role of the European Court of Human Rights, as well as case law under the Revised European Social Charter with its associated collective complaints mechanism. As stated by the above mentioned $\mathrm{CoE}$ report,

\footnotetext{
'it is the Revised European Social Charter which gave a special emphasis to the housing problems of vulnerable social groups, which were reinforced by the CoE's Revised Strategy for Social Cohesion' (Council of Europe 2008).
}

Nevertheless, none of these frameworks have made explicit mention of energy poverty. While they have helped address the driving forces of the condition via their specific sectoral policies, the lack of an integrated EU perspective has constantly undermined member state-level efforts to tackle domestic energy deprivation via an ambitious and comprehensive approach.

\section{Initial efforts to establish an energy poverty policy: The Third Energy Package}

The notion of 'energy poverty' finally entered the vocabulary of the EU in 2009, after years of lobbying and advocacy work by a number of international organizations, academics and political groups. The 
institutional framework for this development was provided by the process of drafting the Third Energy Package, when political action within the European Parliament led to the integration of energy poverty concerns within the Directives 2009/72/EC and 2009/73/EC of the European Parliament and of the Council, 'concerning common rules for the internal market in electricity and natural gas supply'. The compromise text of the directives recognized the existence of a 'growing' energy poverty problem in Europe, requiring member states 'who are affected and which have not yet done so' to ensure the necessary energy supply for vulnerable customers, 'aiming at decreasing the number of people' suffering from this situation. National governments were subsequently asked to formulate 'appropriate measures' to address energy poverty, including the development of national energy action plans. It was noted that:

\footnotetext{
'In doing so, an integrated approach such as in the framework of social policy, could be used and measures could include social policies or energy efficiency improvements for housing. At the very least, this Directive should allow national policies in favour of vulnerable customers' (European Parliament 2009).
}

The increasing prominence of energy poverty within the EU political sphere during this period wasreflected in the Opinion on 'Energy poverty in the context of liberalization and the economic crisis', issued by the European Economic and Social Committee (EESC) on the $14^{\text {th }}$ of July 2010 . Having concluded that 'energy poverty affects the energy sector' while also impacting 'health, consumer affairs and housing', the Committee suggested that 'the EU adopt a common general definition of energy poverty that can then be adapted by each Member State'. It furthermore proposed that 'existing statistics should be harmonized so that the most rigorous assessment possible can be made of the energy poverty situation in Europe'. While emphasizing that 'the number of families affected by energy poverty in Europe could increase', the Committee insisted that 'it would make sense to set up a European Energy Poverty Monitoring Centre, which could fit within an existing body such as the Agency for the Cooperation of Energy Regulators'.

Article 2.7 of the Committee's conclusions pointed out that 'energy poverty is caused by a combination of three factors: low income, inadequate building quality and high energy prices'. During an in- 
formal meeting of EU energy ministers on the $6^{\text {th }}$ of September 2010, the European Commission agreed to produce a report presenting a definition of vulnerable energy customers. According to a subsequent news item:

\footnotetext{
'The meeting, convened by Paul Magnette, Belgian climate and energy minister, saw a rare debate on energy poverty ... "This was the first time in 10 years that the issue of consumers was directly addressed by energy ministers", said Magnette ... Energy poverty is an everyday problem for over 50 million Europeans who are estimated to be unable to pay their energy bills and maintain comfortable living standards, Magnette said ... The idea is not to harmonise social policy, which is for the most part a national competence, Magnette told journalists after the two-day meeting. But he said the EU must acknowledge the problem and see whether there is a need to propose a new piece of legislation or change existing measures' (Euractiv 2010).
}

The Commission's report, published at the end of November 2010 , listed existing and future EU energy policies which are likely to affect the manner in which consumers' interests are taken into account in energy policy. It emphasized the importance of mechanisms such as energy ombudsmen, complaint boards and consumer protection authorities in dealing 'efficiently with complaints and facilitate outof-court dispute settlements' (European Commission 2010). It also encouraged 'Member States to adopt appropriate long-term policy solutions, and not only temporary relief' so as to 'replace direct subsidies for high energy bills with a support for improving the energy quality of the dwellings' (ibid). While pointing out that 'energy efficiency measures should be an integral part of welfare policies', the report also underscored that:

\footnotetext{
'There is no consensus on what actually constitutes energy poverty ... One possible way to quantify the number or proportion of households struggling to settle their energy bills is to try to count the households that spend more than a pre-defined threshold share of their overall consumption expenditure on energy products. An alternative method could focus on those households that have (or have had in recent times) payment difficulties or are in arrears with energy bill payments. Given the diverse situations of energy consumers in different parts of the EU, the Commission does not consider it appropriate at this stage to propose a European definition of energy poverty or of vulnerable customers' (ibid).
}

The findings of the report were to be followed up at a subsequent Energy Council meeting, when the Commission Report would be scrutinized. However, as pointed out by CECODHAS Housing Eu- 
rope - the European Federation of Public, Co-operative and Social Housing:

\footnotetext{
'While the Informal Energy Council in September was dedicated to the most vulnerable energy consumers as well as the phenomenon of energy poverty, the formal Energy Council of December $3^{\text {rd }}$ has adopted conclusions on "an Energy Policy for Consumers" which does not fully recognize the complexity and accurateness of the phenomenon of energy poverty' (CECODHAS Housing Europe 2010).
}

Thus, despite an ambitious departure, initial efforts to establish a pan-European energy poverty policy were unsuccessful. The reasons for this are unclear, although there is evidence to suggest that one of the decisive roles was played by background lobbying from the governments of several powerful member states (such as Germany), which did not have an explicit national-level energy poverty approach; for such states, the pan-European recognition of a 'new' type of deprivation could have caused significant political difficulties due to the need to recognize a distinct new group of vulnerable people in the face of energy price increases and sector restructuring commitments brought about by the low-carbon energy transition.

\section{Developments after the 2010 Energy Council: The EESC takes the lead, followed by the Commission}

In contrast to the Energy Council and Commission's reluctance to tackle energy poverty - even when the issue was explicitly put on the political agenda - the European Parliament took a more decisive approach. On the $15^{\text {th }}$ December 2010, it adopted a resolution on the Revision of the Energy Efficiency Action Plan, which states that the Parliament:

\footnotetext{
... 'believes it is essential that the homes of energy poor households are improved to the highest possible energy efficiency standards and without raising the daily costs for the energy poor; Stresses that this will often require substantial investment in homes but will on the same time generate a lot of non energy benefits, e.g. by reduced mortality, improved general wellbeing, lower levels of indebtedness and reducing healthcare costs by reducing indoor pollution and thermal stress' (European Parliament 2010).
}

More significantly, the EESC continued to maintain a vocal political debate on the subject, while regularly issuing opinions that called 
for the Union's institutions to take a more decisive stance on the issue. In a way, the EESC set the agenda and maintained the focus of political debates on the topic, despite having little executive or legislative influence. In October 2012, for example, the EESC coorganized a conference together with the European Local Inclusion and Social Action Network, which was accompanied by news reports that 'no country in the EU had been spared rising energy prices' (EESC 2012). Cases such as that of Latvia - where energy costs had recently increased by 27 in 2011 - were cited, in addition to the predicted rise of German energy prices by up to 15 per cent, as well as the fact that 42 per cent of French households were reported to have 'cut back on heating their homes to save on energy bills'. The EESC's president Staffan Nilsson was quoted as emphasizing the need for:

\footnotetext{
'determined action at EU level to combat energy poverty: the EU could not ignore a problem that affected up to 125 million Europeans ... Mr Nilsson reiterated that adopting an EU-wide definition of the phenomenon should be the first step in recognizing and mapping the issue. This had to be flexible and not a rigid, one-size-fits-all definition ... Rather than opt for a top-down definition of fuel poverty, the authorities should be given the latitude to offer tailormade solutions' (EESC 2012).
}

These claims reflect the broader tone of the EESC's opinions on this and other matters of EU energy policy, where one can observe a consistent line of argument in favour of a comprehensive strategy, involving multiple stakeholders and taking into account the need for simultaneous action in several different sectors. In line with this determination, the EESC's trans-sectoral 'Study group for co-ordinate European measures to prevent and combat energy poverty' organized a hearing on energy poverty issues at the beginning of July 2013. It hosted members of numerous government bodies, commercial organizations and advocacy groups, including representatives of Eurelectric's Retail Customers Unit, Euro gas (an association representing the European gas wholesale, retail and distribution sectors), Consumer Futures (a UK consumer representation group), the French Red Cross, the European Anti-Poverty Network(an advocacy network of groups and individuals working against poverty) and CECODHAS Housing Europe. Presentations at the hearing highlighted the highly divergent views that some of these organizations 
hold on issues of domestic energy deprivation: From the rather narrow, specific and direct understandings elaborated by representatives of the commercial sector, to the humanitarian concerns asserted by many socially-oriented international non-governmental organizations. Overall, the hearing marked a step change from the level of previous debates on the subject, since it brought forth specific ideas about the detection, measurement and monitoring of energy poverty at the European scale, as well as the need for acknowledging and addressing the reality of the problem via joint action: The proposal for establishing an EU energy poverty observatory was elaborated in further detail, accompanied by the idea to create an 'European energy security and solidarity pact'.

It is not true to say, however, that other EU bodies with greater policy-making influence have not been involved in calls to act on this issue. In January 2013, for example, the European Parliament's Committee on Industry, Research and Energy, adopted a motion for a resolution on the 'Energy Roadmap2050' - a communication produced by the European Commission in 2011, which itself stated that 'vulnerable consumers are best protected from energy poverty through a full implementation by Member States of the existing EU energy legislation and use of innovative energy efficiency solutions' while emphasizing that 'the social aspects of energy pricing should be reflected in the energy policy of Member States' since 'energy poverty is one of the sources of poverty in Europe' (European Commission 2011).In this document, the Parliament:

\footnotetext{
... 'welcomes the inclusion of the social dimension in the Energy Roadmap 2050; considers that, in this respect, special attention should be given to energy poverty and employment; insists, with regard to energy poverty, that energy should be affordable for all, and calls on the Commission and the Member States, and on local authorities and competent social bodies, to work together on tailored solutions to counter such issues as electricity and heat poverty, with a special emphasis on low-income, vulnerable households that are most affected by higher energy prices' (European Parliament 2013).
}

Having emphasized that energy efficiency and savings are' one of the most effective ways to reduce energy bills', the motion also called for the promotion and development of such measures in addition to the stimulation of ' demand- and supply-side actions and creating awareness campaigns' (ibid) towards the enhancement of be- 
havior change. A review of "national measures such as taxation, public procurement and heat pricing' was also suggested, especially in the contexts where they 'are hindering' energy efficiency investment or the 'optimization of heat production and use' (ibid).The motion also asked member states to 'report on a regular basis on actions taken to protect households from rising energy bills and energy poverty' while emphasizing the need for a 'highly skilled workforce ready to play its part in the energy transition' (ibid). Appeals for a broader and more inclusive dialogue in relation to the social aspects of the Energy Roadmap were also made.

It is worth pointing out that the motion was one of the first EUlevel documents to explicitly connect social welfare issues and decarbonization. The need for developing a strategy sensitive to the situation of more vulnerable member states was underlined in order to prevent a'a massive increase in energy poverty'. In an incorrect transposition of the UK definition, energy poverty was designated as a situation in which over 10 per cent of a household's budget is actually spent on energy (as opposed to needing to spend 10 per cent on energy - see Boardman 2010). The decision to highlight the wider structural dimensions of domestic energy deprivation reflects the tone of several recent public discussions on related issues in the European Parliament. In late 2012, for example, Polish MEP Wojciech Olejniczak called for 'extra measures to protect rural areas', which he felt were the 'most threatened by energy poverty'. Speaking at a parliamentary debate on EU energy policy towards rural regions, he said that:

\footnotetext{
'The EU needs to review rural energy as part of overall energy policy ... The focus of EU energy policy should not be only on large infrastructure projects, but should include decentralised energy and regional and local levels' (The Parliament 2012).
}

However, the Energy Roadmap is not the only EC activity in the energy poverty domain. Following the Fourth Citizens Energy Forum (CEF) in London-an annual gathering of energy regulators which features representatives of, inter alia, national energy regulators, industry bodies and consumer associations - the EC established the Vulnerable Consumer Working Group (VCWG): A collaborative effort between two Commission services (the Directorate General 
for Energy and the Directorate General for Health and Consumers) aimed at working together closely with the CEF in supporting the implementation of the Third Energy Package. The institutional setup of this body has allowed for the EC to work closely with consumer associations (such as BEUC - the European Consumer Organization), public bodies/institutions (the Council of European Energy Regulators, Ministries, Ombudsmen), industry (Eurogas, Eureletric) and academia in influencing the European agenda on issues such as consumer protection and energy poverty. Its discussions have offered the opportunity for many of these actors to present their views about the EC's and MS's adoption of EU energy legislation in the domain of consumer vulnerability to energy price increases and market liberalization. As such, they have helped affirm the centrality of the notion of 'vulnerability'- both as an explanatory concept and a policy framework - in the process of transforming the European energy market.

Just like the EESC, the VCWG's work has generated pathbreaking policy discourses and agendas in the European energy poverty domain. Its focus on the notion of vulnerability has moved the debate on the subject beyond the static notion of 'poverty' onto more complex understandings of the inherently dynamic driving forces of deprivation. It has also allowed for an emphasis on processes happening at the scale of individual households - as opposed to commercial and industrial consumers - even though the Third Energy Package can technically be extended to encompass all demand-related activities. The Group has also opened up a broadbased discussion about the need to identify and target households that require assistance with respect to meeting their energy needs. Despite the limitations on its mandate posed by the provisions of the Third Energy Package - which mean that any direct financial measures to benefit vulnerable consumers must not undermine the completion of the free internal market, or endanger competition there has been an insistence that companies should provide inclusive, distinct and appropriate forms of support. The VCWG has also reviewed indirect methods of assistance, while providing and promoting examples of good practice. It has often emphasized the importance of energy efficiency measures as a principal method for addressing the lack of adequate space heating or cooling, as well as 
issues with the consumer appliance stock. The outcomes of the Group's work in the vulnerability domain have been reflected in, inter alia, the provisions made by the EC's Internal Energy Market Communication, released in autumn 2012.

To a certain extent, the action of EU organizations in the energy poverty domain has been influenced by international nongovernmental organizations working in this field. Particularly notable have been the activities of advocacy groups such as INFORSE, the International Union of Tenants, and the European Federation of Public Service Unions, and INFORSE; this is in addition to the highprofile work of the aforementioned ELISAN, EAPN and CECODHAS Housing Europe. A good illustration of the prominence of the energy poverty agenda in the work of these organizations is provided by the Resolution on Energy Strategy for Europe 2011-2020, adopted by the Executive Committee of the European Trade Union Confederation (ETUC) in late 2010. It states that:

... 'National Energy Actions Plans should focus more on measures to reduce "energy poverty", [a] concept that must get a common European definition. The effectiveness of these measures could be increased through a better coordination with the National Action Plans for social inclusion and social protection' (ETUC 2010).

Industry-funded lobby groups such as the World Coal Association have also voiced concerns over the rise of energy poverty, albeit their arguments have mostly been articulated in opposition to decarbonization-driven energy price increases. It is also worth noting the work of the Central and Eastern Europe Bank watch Network, Southeastern Europe Change Net and the World Wildlife Fund in the Balkans, where such organizations have urged EU funds to urge international development banks to invest in energy efficiency as a method of alleviating energy poverty. Also of significance in this regard is the growing number of EU-supported projects aimed at generating practical and scientific knowledge on the topic. In recent years, such initiatives have included FinSH (Financial and Support Instruments for fuel Poverty in Social Housing - 2007-2010) Energy Ambassadors (Campaign to fight against fuel poverty and raise awareness on energy efficiency and energy savings - 2009-2011), EC-LINC (Energy Check for Low Income Households - 2011-2014) and ACHIEVE (Actions in low income households to improve ener- 
gy efficiency through visits and energy diagnosis - 2011-2014). Although such work has mainly been practitioner-led and - orientated due to being funded by the Intelligent Energy Europe programme, which has a specific remit in this regard - it should be pointed out that the EVALUATE project (Energy Vulnerability and Urban Transitions in Europe, 2013-2018) has a principally scientific remit and is supported by the European Research Council.

\section{Conclusions: A precarious future}

The European Union (EU) has become increasingly committed to tackling energy poverty through direct and indirect regulation, even though many uncertainties remain unresolved in its attempts to address the complex needs of vulnerable groups. The rise of income inequality as a result of the economic recession has increased the demand for new policies in this domain, partly as a result of the pronounced existence of energy poverty-related problems in Southern and Eastern European states. In addition to the indirect energy poverty-relevant regulation arising as a direct consequence of EU-level actions in the housing, energy and - to a lesser extent - social domains -a key impetus for more direct government policy in this sphere has been provided by the mechanisms stemming from the Third Energy Package.

In this context, it is worth noting the significant - and relatively fast - development of a distinctive EU agenda on energy poverty, accompanied by a range of groundbreaking steps in terms of defining the normative procedures through which the condition is to be recognized and addressed. In this process, it is possible to observe a process of policy mobility between the national scale - where most energy poverty conceptual frameworks and policies were initially developed - and that of the EU, which serves as a forum for integrating and recombining such registers, only to return them back to member states for implementation. Thus, many components of EU energy policy act as 'immutable mobiles' (Latour 1997), which demonstrate the importance of a social-constructivist understanding of policy mobilities-and-mutations, sensitive to the constitutive roles of spatiotemporal context' (Peck 2011: 773). In response to some of 
the starting positions that we aimed to investigate in this contribution, it can be said that agenda-shaping in the EU poverty domain has been mainly driven from above and has been highly contingent on attempts to 'define' and 'identify' the problem. There is little evidence to suggest, however, that particular events or dynamics such as the enlargement of the EU or the protests in Bulgaria - have provided a central impetus for European action in this domain. As such, the weak between them and other EU energy policies is weak, mainly because they have been driven by institutions such as the EESC, which has traditionally sat outside this policy domain. Only in recent years have energy poverty concerns started to enter mainstream EU policy agendas, principally as a result of the Commision's efforts surrounding the implementation of the Third Energy Package.

Overall, current energy poverty policies in the EU context vary drastically from country to country, while lacking inter-sectoral coordination in terms of energy (affordability and accessibility), social welfare and housing policies (Bouzarovski 2013). The need for the creation of policy initiatives that will specifically tackle energy poverty as a multidimensional and cross-sectoral phenomenon is therefore likely to become a key site of political action in the years to come. This may entail, inter alia, the development of specific EU regulation to fight energy poverty, as well as the incorporation of energy poverty indicators in monitoring and evaluation mechanisms at the EU and national level. Another distinct possibility is the explicit integration of the energy-poverty-housing nexus in cohesion policy: A step that is of particular importance for new and forthcoming member states, where the rise of domestic energy deprivation is largely predicated upon access to adequate housing and networked infrastructure.

\section{References:}

Boardman, B. (2010) Fixing Fuel Poverty: Challenges and Solutions. Earthscan, London. Bouzarovski, S., Petrova. S., and Sarlamanov, S. (2012) Energy poverty policies in the EU: A critical perspective. Energy Policy 49: 76-82.

Bouzarovski, S. (2013) Energy poverty in the European Union: Landscapes of vulnerability. Wiley Interdisciplinary Reviews. In print. 
CECODHAS Housing Europe (2010) Energy poverty: no mention at the Energy Council. http://www .housingeurope.eu/news/1703. Accessed on 01/08/2013.

Campbell, R. (1993) Fuel poverty and government response. Social Policy \& Administration 27: 58-70.

Cobb, R.W. and Elder, C.D. (1983) Participation in American Politics: The Dynamics of Agenda-Building. The Johns Hopkins University Press, Baltimore.

Council of Europe (2008) Housing Policy and Vulnerable Social Groups. Council of Europe, Strasbourg.

EESC (2012) EESC president argues for urgent EU action to eradicate energy poverty. http://europa.eu/rapid/press-release_CES-12-74_en.htm. Accessed on 01/08/2013.

ETUC (2010) Resolution on Energy Strategy for Europe 2011-2020. http://www .etuc.org/a/7952. Accessed on 01/08/2013.

Euractiv (2010) EU to define 'vulnerable' energy customers. http://www .euractiv .com/energy/eu-define-vulnerable-energy-cust-news-497583. Accessed on $01 / 08 / 2013$.

European Commission (2010) Commission Staff Working Paper: An Energy Policy for Consumers. European Commission, Brussels.

European Commission (2011) Communication from the Commission to the European Parliament, the Council, the European Social and Economic Committee and the Committee for the Regions. Energy Roadmap 2050 http://eur-

lex.europa.eu/LexUriServ/LexUriServ.do?uri=CELEX:52011DC0885:EN:NOT. Accessed on $01 / 08 / 2013$.

European Parliament (2009) Directive 2009/72/EC of the European Parliament and of the Council of 13 July 2009 concerning common rules for the internal market in electricity and repealing Directive 2003/54/EC (Text with EEA relevance).

http://eurlex.europa.eu/LexUriServ/LexUriServ.do?uri=CELEX:32009L0072:EN:NOT. Accessed on 01/08/13.

European Parliament (2010) REPORT on the Revision of the Energy Efficiency Action Plan A7-0331/2010. http://www .europarl.europa.eu/sides/getDoc .do?language=EN\&reference=A7-0331/2010. Accessed on 01/08/2013.

European Parliament (2013) REPORT the Energy roadmap 2050, a Future with Energy. http://www .europarl.europa.eu/sides/getDoc .do?pubRef=-//EP//TEXT+REPORT+A7-20130035+0+DOC+XML+V0//EN. Accessed on 01/08/2013

Hills, J. (2012) Getting the Measure of Fuel Poverty: Final Report of the Fuel Poverty Review. Centre for Analysis of Social Exclusion, London School of Economics and Political Science, London.

Jansz, A.and Guertler, P. (2012)The Impact on the Fuel Poor of the Reduction in Fuel Poverty Budgets in England. Association for the Conservation of Energy, London.

McCormick, J. (2001) Environmental Policy in the European Union.

Latour, B. (1997) Science in Action, Harvard, Cambridge MA. Palgrave Macmillan, Basingstoke.

McCann, E. and Ward, K. (2012) Policy Assemblages, Mobilities and Mutations: Toward a Multidisciplinary Conversation. Political Studies Review 10: 325-332.

Peck, J. (2011) Geographies of Policy: From Transfer-Diffusion to Mobility-Mutation. Progress in Human Geography 35: 773-797.

The Parliament (2012) MEPs Call for Action to Combat 'Energy Poverty'. MEPs call for action to combat 'energy poverty'. http://www.theparliament.com/latestnews/article/newsarticle/meps-call-for-action-to-combat-energy-poverty/\#.UfesXlO5feY. Accessed on 01/08/2013.

Tosun, J., Schmitt,S. and Schulze, K., this volume. Building the EU's agenda in energy policy making: An introduction. 
Tosun, J. and Solorio, I. (2011) Exploring the energy-environment relationship in the EU: Perspectives and challenges for theorizing and empirical analysis. European Integration Online Papers 15: 1-15. 